\title{
Aerial Radiological Measuring Survey of the Cooper Nuclear Station August 1972
}

\author{
EG\&G, Ine., Las Vegas, Nevada
}

This reporf is part of a series on the continuing activities of the Aerial Radiological Measuring System operated for the U. S. Aromic Energy Commission. The ARMS program is monaged by the Division of Operahional Safety and is a cooperative effort among various offices and divisions of the Commission. 


\section{DISCLAIMER}

This report was prepared as an account of work sponsored by an agency of the United States Government. Neither the United States Government nor any agency Thereof, nor any of their employees, makes any warranty, express or implied, or assumes any legal liability or responsibility for the accuracy, completeness, or usefulness of any information, apparatus, product, or process disclosed, or represents that its use would not infringe privately owned rights. Reference herein to any specific commercial product, process, or service by trade name, trademark, manufacturer, or otherwise does not necessarily constitute or imply its endorsement, recommendation, or favoring by the United States Government or any agency thereof. The views and opinions of authors expressed herein do not necessarily state or reflect those of the United States Government or any agency thereof. 


\section{DISCLAIMER}

Portions of this document may be illegible in electronic image products. Images are produced from the best available original document. 


\begin{abstract}
The Aerial Radiological Measuring System (ARMS) was used to survey the area surrounding the Cooper Nuclear Station during August 1972, prior to reactor start-up. The survey measured terrestrial gamma radiation.

A high-sensitivity detection system collected gamma-ray spectral and gross-count data. The data were then computer processed into a map of a 700 square mile area showing isoexposure contours three feet above the ground. Exposure rates and isotopes identified are consistent with normal terrestrial background radiation.
\end{abstract}




\section{ACKNOWLEDGMENTS}

Special appreciation is given to L.J. Deal (Assistant Director, DOS/Health Protection, USAEC) for his support and encouragement in this program. 


\section{CONTENTS}

1. INTRODUCTION $\bullet \quad . \quad \cdot \quad \cdot \quad \cdot \quad \cdot \quad \cdot \quad \cdot \quad \cdot \quad 1$

1.1 Identification of Surveyed Plant and Area . . 1

1.2 ARMS Program . . . . . . . . . 1

1.3 ARMS Equipment and Procedures . . . . 1

1.4 Reduction and Presentation of Data . . . . 4

2. REACTOR AND SITE CHARACTERISTICS . . . . 5

2.1 Reactor Characteristics . . . . . . 5

2.2 Site Area Characteristics . . . . . . 6

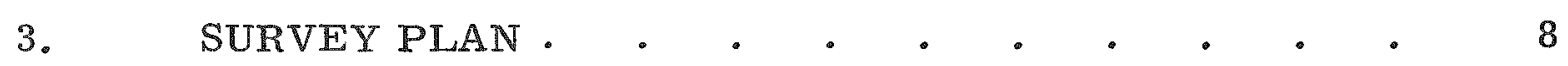

3.1 Specification of Flight Lines . . . . . 8

3.2 Coordination with Local Authorities . . . 8

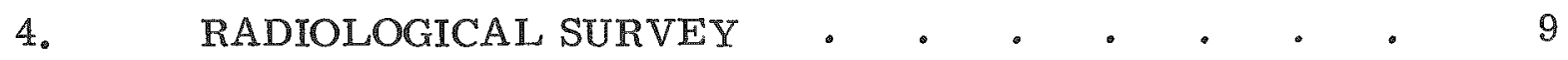

4. 1 Survey Missions . . . . . . . . 9

4.2 Gross-Count Data . . . . . . . 99

4.3 Spectral Data . . . . . . . . . 9

5. SUMMARY AND CONCLUSIONS . . . . . . 14 


\section{INTRODUCTION}

1.1 Identification of Surveyed Plant and Area

The Aerial Radiological Measuring System (ARMS) (Ref. 1) operated by EG\&G, Inc., Las Vegas, Nevada, for the U. S. Atomic Energy Commission was used to survey an extensive area surrounding the Cooper Nuclear Station during August 1972. The Cooper Station, operated by the Nebraska Public Power District, is located near Brownville, Nebraska. The size of the survey area was 700 square miles.

\section{$1.2 \quad$ ARMS Program}

The present survey was made as part of a continuing nationwide ARMS program started in 1958 to monitor radiation levels surrounding facilities producing or utilizing radioactive materials. This is the first such survey performed in the Cooper Station area.

The detection system on board the aircraft collects gamma-ray gross-count and spectral data on each flight line of the survey. The gamma radiation and aircraft position information are processed by a computer into an isoexposure contour map of the area surveyed.

\subsection{ARMS Equipment and Procedures}

The ARMS aircraft and its on-board radiation detection equipment were used in the survey. Since the ARMS equipment and procedures have been discussed in detail elsewhere (Ref. 1), they will only be described briefly here.

The ARMS surveys are flown in a Beechcraft Twin Bonanza at an altitude of 300 to 500 feet above terrain at a ground speed of about 140 knots $(235 \mathrm{ft} / \mathrm{sec})$. The ground position of the aircraft and its altitude above terrain are measured and recorded every other second by a radar navigation computer system. The position and altitude measurements are accurate to $\pm 350 \mathrm{ft}$ and $\pm 5 \mathrm{ft}$, respectively.

A typical flight pattern consists of a series of parallel lines spaced one nautical mile (6080 feet) apart, covering all of the land area within a twelve and one-half nautical mile radius of the facility. 
At an altitude of 500 feet, the field of view of the detectors is approximately $1 / 4$ mile wide for a mean gamma energy of naturally occurring isotopes.

The aerial radiation measurements are of two distinct types, made simultaneously: (1) gross gamma count (intensity) measurements and (2) gamma spectral measurements. The detector system consists of an array of lourteen $4 \times 4$ in. NaI (Tl) scintillation crystals, each coupled to its own photomultiplier assembly. The detector system output is directed both to the gross gamma count computing system and to the multichannel spectrum analyzer. The data collecting system is shown in Figure 1.

The gross gamma count system consists of an amplifierdiscriminator-computer unit that counts and records the total number of gamma-rays of energy greater than $50 \mathrm{keV}$ that are detected during a 1-second time interval. The gross gamma count rate (number of gamma-rays detected per second) is digitally recorded along with aircraft position and altitude every other second. Aircraft position data are supplied by a track navigational computer and doppler radar. Altitude above terrain is measured with a radar altimeter. As a backup and complement to the digital recording of the gross-count data, a record is made on a continuous strip chart of both gross gamma count rate and radar altitude as a function of distance. Typical gross-count rates for natural background are several thousand per second.

Whereas the gross gamma count data specify the intensity of radiation as a function of position, the gamma spectral data are useful in identifying particular radioactive isotopes. A pulse-height analyzer automatically sorts detected gamma-rays according to energy, thereby generating a number per unit-energy versus energy spectrum. Although gamma rays occur only at well known discrete energies characteristic of the emitting species, air scattering tends to smear the detected distribution. Nevertheless, the characteristic peaks that permit isotope identification are readily observable. In wide area surveys the typical acquisition time for a gamma-ray spectrum is several minutes; thus the spectrum represents the average radiological properties of a tract several miles in length. However, if an area of interest is indicated by an increase in the gross gamma count rate, spectral data acquisition times of only a few seconds are used to isolate the area spatially. If further investigation is warranted, a ground mobile unit with equipment similar to that in the aircrait is available to provide greater spatial and energy resolution.

In addition to the equipment just described, the ARMS aircraft also carries an air sampling and analysis system for the measurement of airborne radioactivity. 


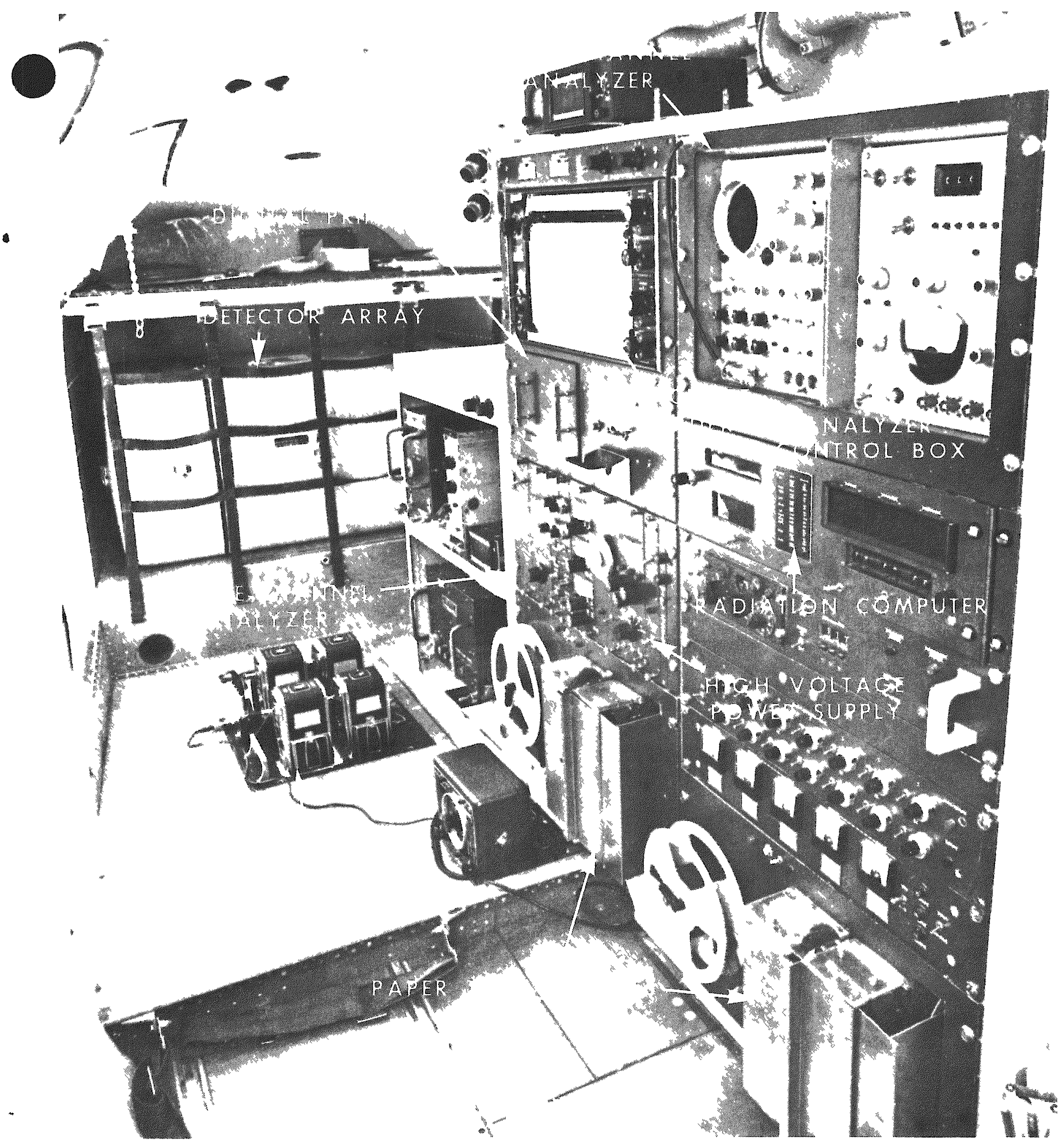

FIGURE 1. View of the interior of the Aerial Radiological Measuring System (ARMS) aircraft showing detector package and electronic data collection system. 


\subsection{Reduction and Presentation of Data}

The raw data from the gross gamma count and the gamma spectral measurements are permanently recorded on paper tape, which is computer processed and analyzed to characterize the radiological properties of the area surveyed. Using an altitude-dependent conversion factor obtained from prior calibration measurements, the raw gross-count rate is converted to exposure rate $(\mu \mathrm{R} / \mathrm{hr}$ ) at three feet above ground.

The exposure rate conversion factor was obtained from repeated flights 200 to 1000 feet above terrain containing known distributions of natural isotopes. Such conversion factors have proved valid over distributed fission product fields, with a variation of less than $25 \%$. In practice, variations of $2 \mu R / h r$ or greater can be reliably observed in repeated flights over the same area. 


\section{REACTOR AND SITE CHARACTERISTICS}

\section{$2.1 \quad$ Reactor Characteristics}

The Cooper Station Reactor is located in Nemaha County, Nebraska, 12 miles east of the town of Auburn.

The principal nuclear contractor is the General Electric Company. The facility is operated by the Nebraska Public Power District.

Table 1 gives the specifications of the reactor facility. At the time of the survey the reactor had not yet commenced operating.

TABLE 1. Reactor facility specifications.

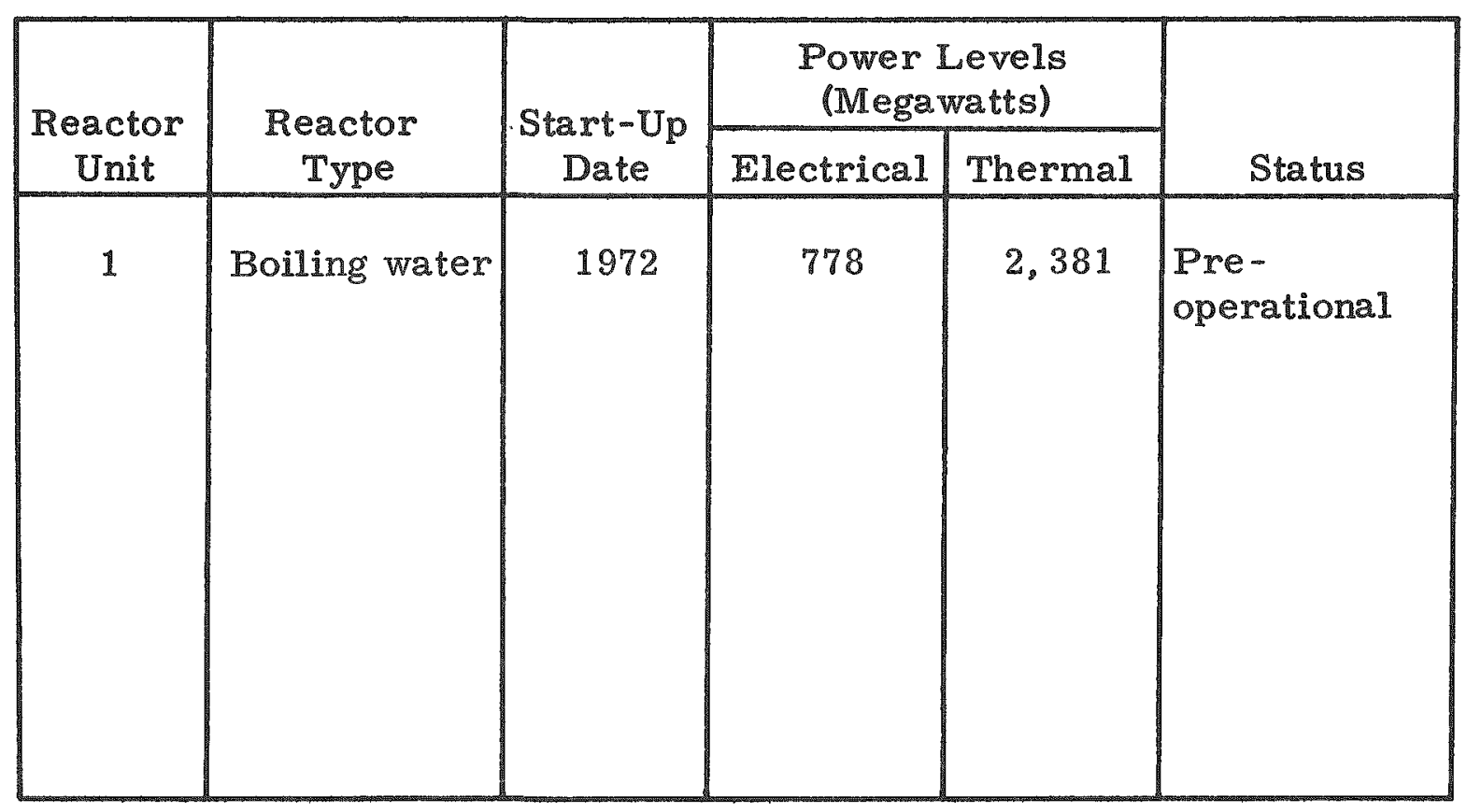




\subsection{Site Area Characteristics}

In general the terrain in the survey area is flat cultivated farmland. The Missouri River runs through the center of the area.

Table 2 lists the towns in the survey area with significant populations, by distance and direction from the reactor site. 
TABLE 2. Principal population centers within the Cooper Nuclear Station area.

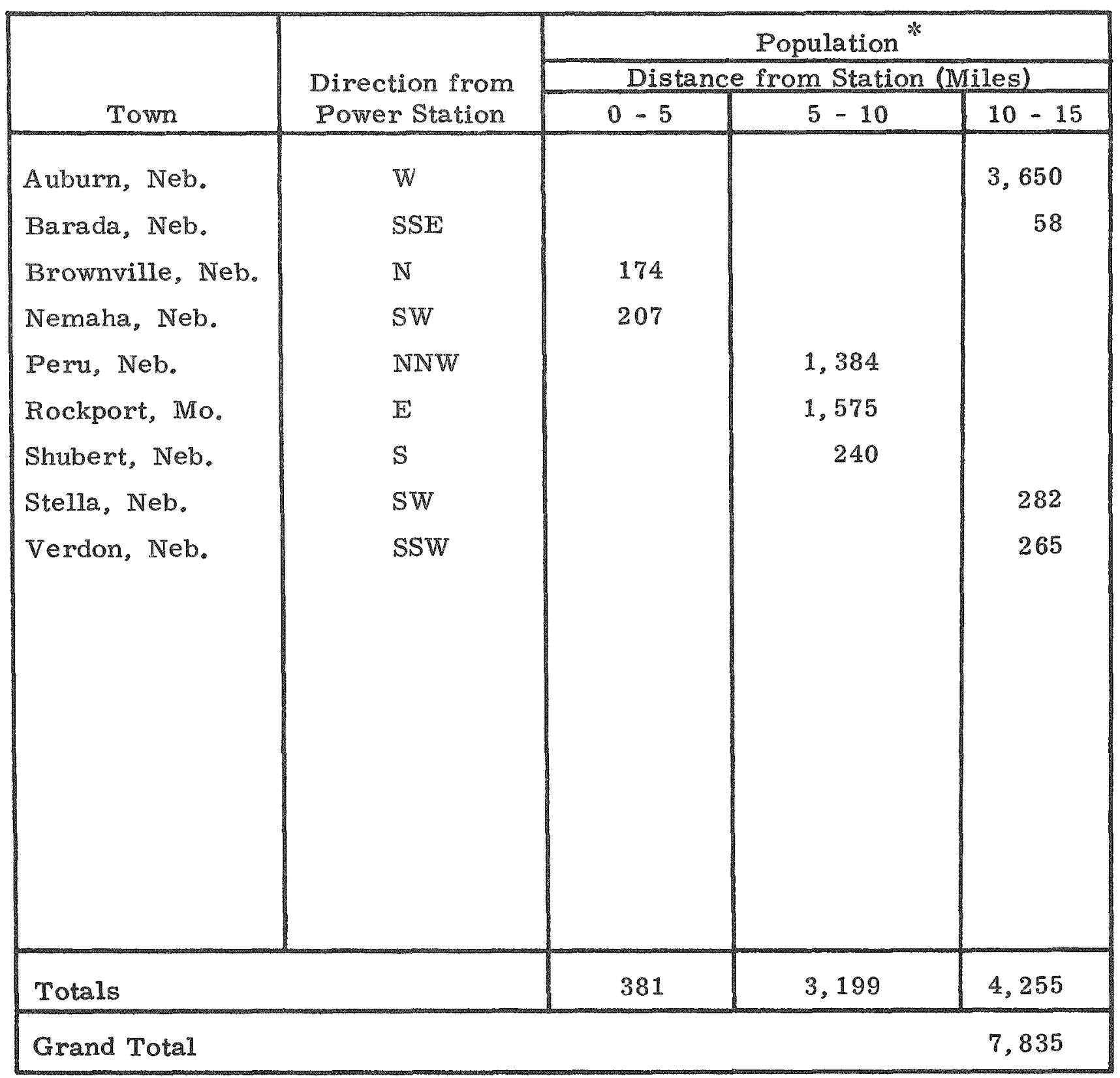

* 1970 census figures (Ref. 2). 


\section{SURVEY PLAN}

\subsection{Specification of Flight Lines}

The flight pattern for the Cooper Station survey consisted of 25 flight lines approximately 25 nautical miles long and spaced one nautical mile apart. The lines were oriented in a north-south direction. Radiation data together with aircraft position and meteorological information were collected along each flight line.

\subsection{Coordination with Local Authorities}

ARMS survey missions are conducted under special waiver from the Federal Aviation Administration. The survey plan was discussed with the appropriate General Aviation District Office, and public announcements were published in the local newspapers prior to the survey operation in accordance with the FAA waiver for low-level flights.

The base of operations for the survey mission was Omaha, Nebraska. 


\section{RADIOLOGICAL SURVEY}

\subsection{Survey Missions}

The aerial survey of the Cooper Station Reactor area was conducted on 11, 12, and 13 August 1972. This survey required a total flying time of 12 hours.

Gross-count and spectral data were simultaneously collected at an altitude of 500 feet. Spectra were accumulated over 4 -minute intervals during which the aircraft traveled approximately 12 miles; consequently, two spectra per line were collected.

\subsection{Gross-Count Data}

As a first step in the analysis of the gross-count data, the background due to nonterrestrial radiation was subtracted. This background. consists of cosmic-ray, aircraft, and airborne radioactivity contributions (Ref. 3). After correction for background, the data were normalized to a standard air mass. The resultant net-count data were then converted to exposure rate in microroentgens per hour ( $\mathrm{R} / \mathrm{hr}$ ) at the 3 -foot level above the ground. The cosmic-ray exposure rate was then added back to the terrestrial exposure rate. Finally, the composite exposure rate data, together with aircraft position information, were processed into an isoexposure contour map for overlay on U. S. Geological Survey topographic maps of the survey area.

An isoexposure map of the Cooper Station area is shown in Figure 2. The data shown on the map include a cosmic radiation contribution of 2 to $4 \mathrm{uR} / \mathrm{hr}$. Spatial resolution of the exposure rate data is determined by the field of view of the detector system, which is about $1 / 4$ mile.

\subsection{Spectral Data}

Spectral data were recorded from about 0.03 to $3.0 \mathrm{MeV}$. The recording system was calibrated prior to takeoff with an yttrium-88 source, which emits two prominent gamma-rays of 0.898 and $1.836 \mathrm{MeV}$. The gain for each crystal in the 14-crystal detector array was set independently. 


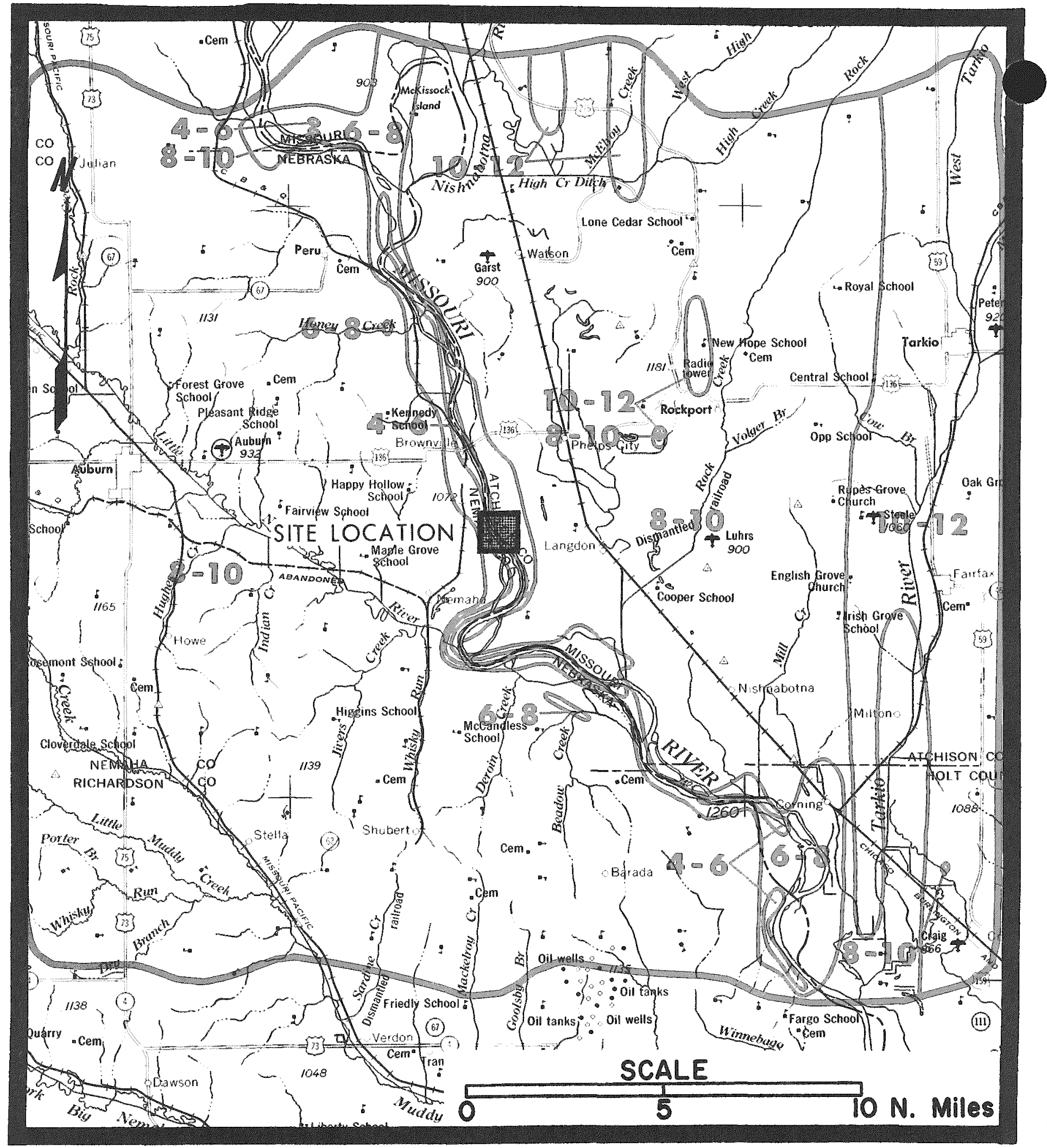

FIGURE 2. Gamma exposure rate contour map of the Cooper Nuclear Station area, August 1972. (Values shown are in units of $u R / h r_{\text {. }}$ ) 
A spectrum typical of those taken during the survey is shown in Figure 3. Table 3 lists the prominent gamma-ray energies and associated source isotopes identified in the spectrum. Differences in shape between spectra taken over different portions of the survey area are minor, and the isotopes identified in all spectra are the same. Only isotopes consistent with normal background radiation are apparent. 


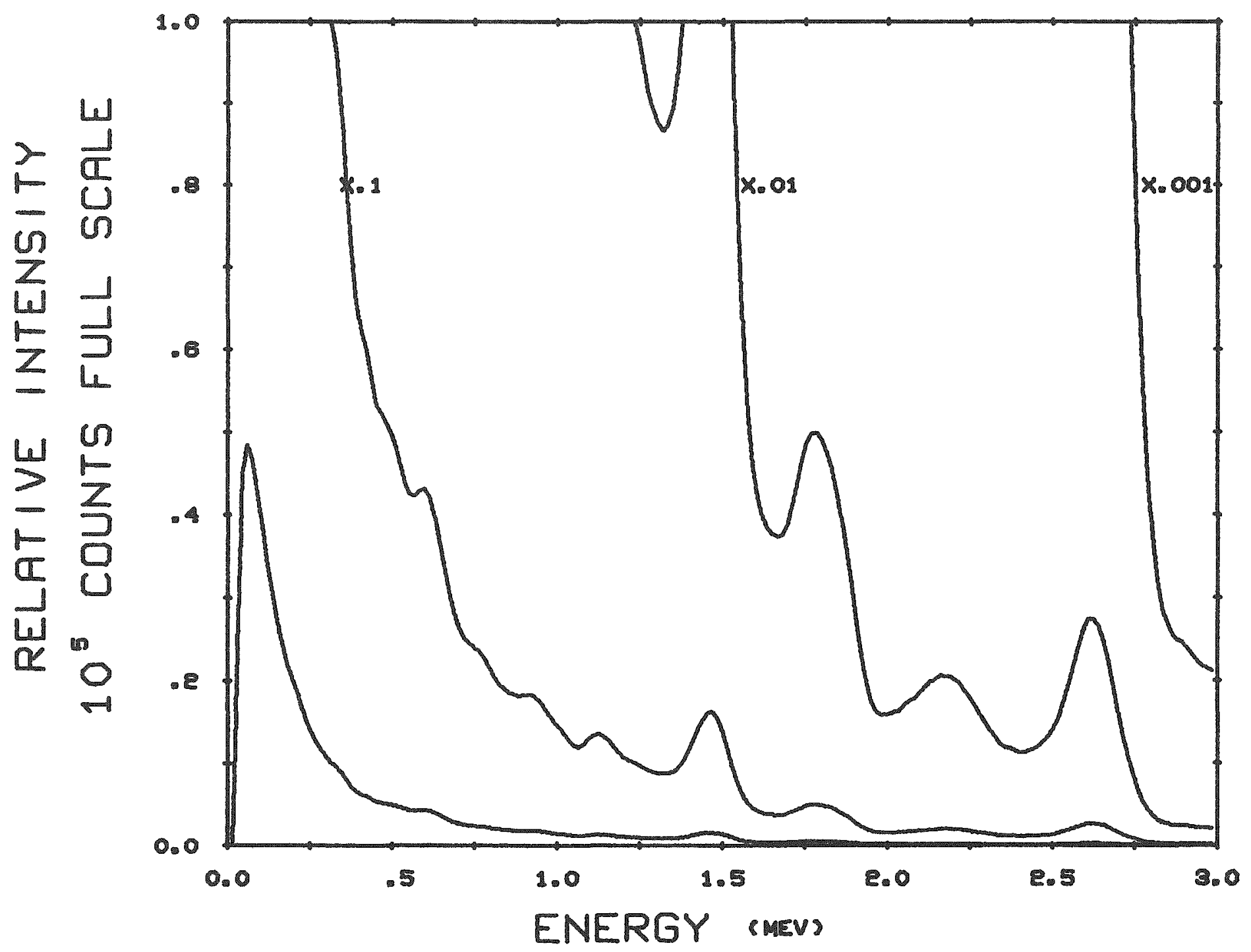

FIGURE 3. Typical gamma pulse height spectrum for survey area. 
TABLE 3. Gamma-ray energies and isotopes consistent with spectral data of Figure 3 .

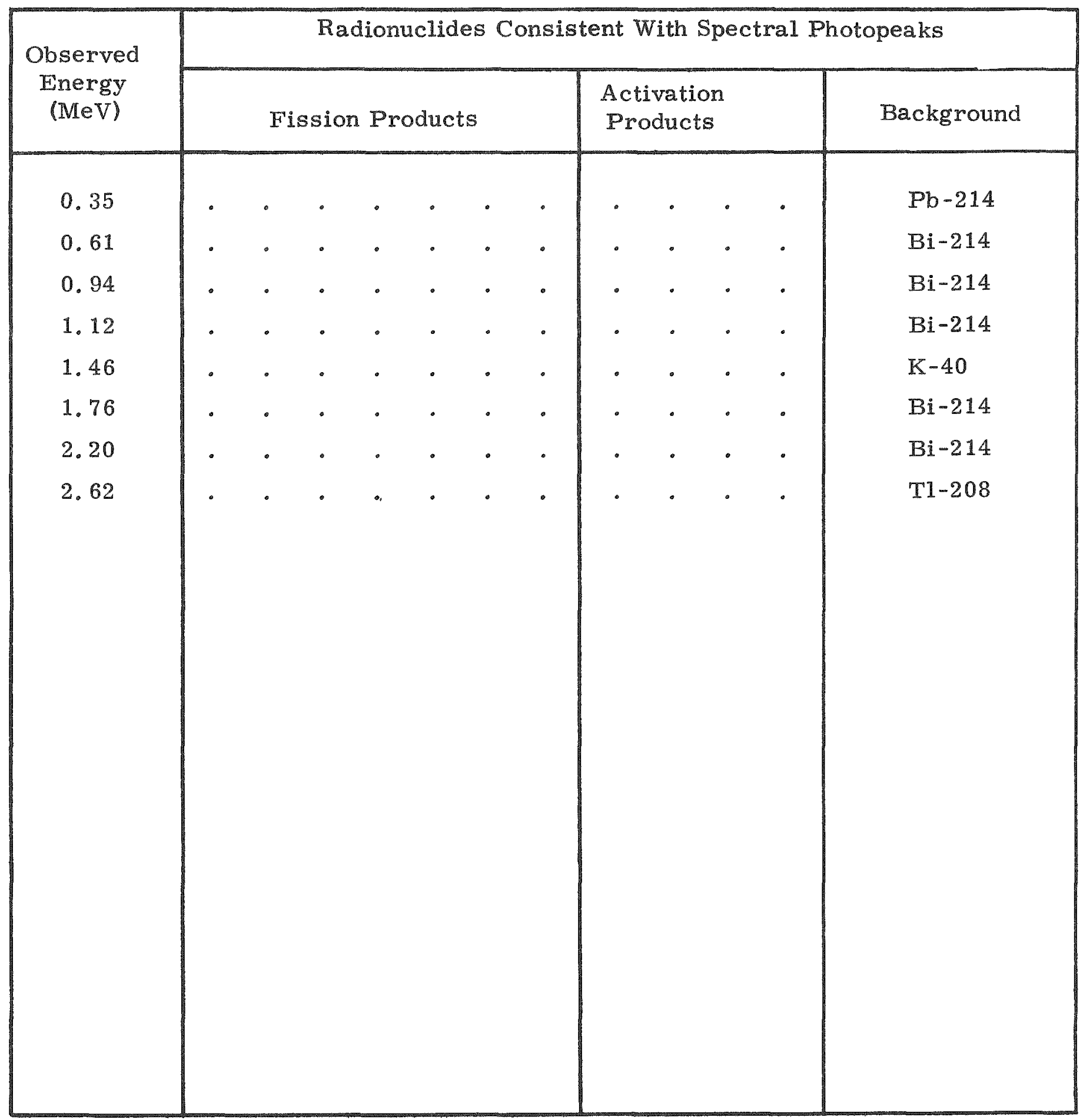




\section{SUMMARY AND CONCLUSIONS}

Since at the time of the survey the Cooper Station Reactor had not yet commenced operating, the survey provided a background radiation map of the reactor area. Exposure rates and radioactive isotopes revealed in the survey are consistent with normal terrestrial background.

The 3 -foot level exposure rates mapped during the survey were mostly in the 6 to $12 \mu \mathrm{R} / \mathrm{hr}$ range. 


\section{REFERENCES}

1. "Aerial Radiological Measuring Systems (ARMS) - Systems and Procedures Employed Through FY71," AEC Report No. ARMS-71.6, in preparation.

2. 1970 Census of Population, Advance Reports PC(VI)-27 and PC(VI)-29, U. S. Dept. of Commerce, Bureau of Census, Dec. 1970.

3. Burson, Z. G., Boyns, P. K., and Fritzsche, A. E., "Technical Procedures for Characterizing the Terrestrial Gamma Radiation Environment by Aerial Surveys, "EG\&G/LVAO Report No. 1183-1559, 1972 . 